\title{
The market for hospital pharmaceuticals in Denmark
}

\author{
GISELA HOSTENKAMP * \\ gih@sam.sdu.dk \\ University of Southern Denmark
}

\begin{abstract}
Pharmaceutical expenditure growth has outpaced GDP and other healthcare expenditure growth during the last decade in Denmark, as in many other OECD countries. A large part of this expenditure growth was due to high growth rates in the market for hospital medicines. However this part of the pharmaceutical market is still poorly understood. The current article describes the market for hospital pharmaceuticals in Denmark, both its organisation and market characteristics.

A salient feature of the Danish market for hospital pharmaceuticals is that procurement is centrally organised. Using data on pharmaceutical expenditures for 2005 to 2009 and real contract prices the article compares market characteristics between the pharmaceutical retail and hospital sector and calculates price and volume indices to decompose expenditure growth and identify the contribution of newly introduced substances.

The article finds that the market for hospital pharmaceuticals is more concentrated and the market share of generics and parallel imports is significantly lower than in the retail sector. While the price increase for pharmaceuticals was larger in the hospital sector than in the retail sector, the majority of expenditure growth was due to an increase in utilisation, reflecting increased hospital activity, and introduction of new substances in the hospital sector.
\end{abstract}

Keywords: Pharmaceuticals, Hospital, Procurement, Denmark, Tendering, Pricing

\section{Introduction}

Pharmaceutical expenditures growth has outpaced GDP and healthcare expenditure growth rates in most OECD countries for the last decade, and Denmark is no exception (OECD 2009). A majority of this increase was due to high growth rates in the market for hospital medicines. Yet, researchers and policy makers have so far concentrated on the pharmaceutical retail sector and there is a lack of knowledge about the market for hospital pharmaceuticals and its organisation. The present article attempts to close this gap by presenting an analysis of the institutional background and developments in the Danish market for hospital medicines between 2005 and 2009.

In many European countries the selection, procurement, pricing and distribution of hospital medicine is radically different to the supply chain that operates in the pharmaceutical retail sector. Payers and industry operate in two very different markets, in which the priorities and criteria applied to buying and selling decisions have little in common (Brereton 1999). Only some European countries control prices for hospital medicines at a national level. In most cases, the methods for containing expenditure growth in the pharmaceutical retail sector such as co-payments, reference pricing, etc., do 
not apply in the hospital sector. Instead a majority of European countries use public tendering approaches at various levels of centralisation to organise procurement of hospital medicines (Leopold et al. 2008). Thus while the current study covers the Danish market it is similar to the procurement systems for hospital medicines that operate in other Nordic countries.

We define as hospital medicines all pharmaceuticals that are administered in a hospital setting, whether in in-patient or out-patient departments, whereas the pharmaceutical retail sector comprises all pharmaceuticals dispensed outside the hospitals in retail or community pharmacies. Compared to the turnover generated in the pharmaceutical retail sector the market for hospital pharmaceuticals has traditionally been rather small. A recent report guessed that hospital medicines on average make up between 10 to $15 \%$ in OECD countries. However the share of hospital medicines is likely to be higher in countries that have a national health service, such as the UK and the Scandinavian countries since there are few private specialists. Paired with recent technological advances in oncology and other specialist areas, which are usually treated in hospital settings, the hospital market is consuming an increasing part of pharmaceutical expenditures suggesting that the market for hospital medicines is becoming increasingly important (OECD 2008). After a decade of annual expenditure growth rates of over $15 \%$, the market for hospital pharmaceuticals in Denmark had reached a market share of almost $40 \%$ of the total Danish pharmaceutical market in terms of expenditures in 2009 (Ministry of Health and Prevention 2009). However there is a lack of knowledge about the factors that contributed to the expenditure increase and their relative importance.

In search for measures to contain pharmaceutical expenditures many EU countries have introduced group purchasing and public tendering approaches to procure hospital medicines. But while the pharmaceutical retail market has been studied extensively, there is little systematic information, even within countries and experts, on the procurement of hospital medicines (OECD 2008). Studying the hospital sector is often complicated by the fact that public statistics do not reflect rebates granted, thus true contract prices are seldom publicly available.

This may be one reason why the existing literature on pricing of hospital medicine, group purchasing and pharmaceutical tendering is quite limited. The existing literature focuses either on the pharmaceutical retail sector or short run expenditure savings. To the author's knowledge there are only two reports commissioned by the European Union and three published articles that describe the use of pharmaceutical tendering for off-patent medicines in several European countries in the pharmaceutical retail sector (Carradinha, 2009;Dylst, 2011;Kanavos, 2009; Tordoff, 2005;Tordoff, 2008). A recent Italian study reviews legal issues associated with tendering hospital medicines and its potential to prevent nepotism and foster competition (Sammarco 2010). Only a few studies assess the impact of tendering and group purchasing of hospital medicines on expenditures empirically. However they are limited in their scope on short-run effects or few hospitals (Milovanovic et al. 2004; Tordoff et al. 2005; Tordoff et al. 2008). These approaches are of little use to assess the performance of tendering procedures in Denmark since pharmaceutical tenders were introduced in the 1990ies, well before our observation period began and only a small fraction is spent on pharmaceuticals that were already marketed then.

Instead the present study seeks to contribute with a description of the procedures to procure hospital medicines and an assessment of its market implications using data on real contract prices from Denmark's public procurement agency AMGROS. During the last 5 years Danish hospitals have on average received 19\% discount off the official pharmacy purchasing price. However, direct price comparisons between the pharmaceutical retail 
and hospital sector are problematic, because many procedures that are routinely based in hospital settings, such as invasive surgery and cancer treatments, depend on hospital-only medicines that are typically not found in retail pharmacies. The present study therefore pursues a new approach to assess the performance of this institutional set-up, by decomposing pharmaceutical expenditure growth between 2005 and 2009 and comparing price developments and measures for market structure to the pharmaceutical retail sector. Policy makers are often interested in this kind of decomposition of expenditure growth to determine to which extend they are justified and reflect higher treatment activity and increased treatment efficiency or whether they are due to pure price increases for old medicines (Rovira et al. 2001).

The rest of the article is organised as follows: Section 2 provides a description of the institutional set-up focussing on the differences between the pharmaceutical retail and hospital sector in Denmark and the organisation of procurement of hospital medicines. Section 3 describes the data and presents the method used for the decomposition of pharmaceutical expenditure growth. Section 4 presents the distribution of expenditures in 2009 and the decomposition analysis. Section 5 discusses the results and concludes.

\section{The Institutional set-up}

In order to sell a pharmaceutical product on the Danish market suppliers need to apply for marketing authorisation at the Danish or European Medicines Agency. Marketing authorisation is granted based on a trade-off between the products efficacy and side effects; the price or efficiency of the medicine is generally not considered. In principle suppliers are free to set the selling price of their products in Denmark, although several regulatory mechanisms have been introduced in the pharmaceutical retail sector over the last decade to influence pricing decisions and to contain pharmaceutical expenditure growth. (Lif 2007)

\subsection{Differences between the pharmaceutical retail and hospital sector}

The organisation and financing of the market for hospital medicines and the pharmaceutical retail sector in Denmark differ fundamentally. In the retail sector there are several mechanisms to affect pharmaceutical price setting through the regulation of reimbursement, including measures such as co-payments, reference pricing, international price comparisons and cost-effectiveness assessments (Danish Medicines Agency 2010; Møller Pedersen 2003). In contrast medicines administered at public hospitals are free of charge to the patient, as in most other European countries, and are publicly financed by the Danish regions, which run the public hospitals. Thus all incentives to affect pharmaceutical prices through reimbursement regulation are ineffective in the hospital sector.

Instead there are several institutions in the hospital sector to limit pharmaceutical expenditures through the limitation of utilisation of secondary health care services. Every region has one or more pharmaceutical and therapeutic committees that prepare treatment guidelines and formulary lists, listing the preferred substances for many routine hospital procedures to control pharmaceutical utilisation in public hospitals (Ministry of Health and Prevention 2009). To implement the guidelines electronic support systems are installed in public hospitals to assist physicians to choose the treatment recommended by the respective region, which should reflect the most efficient treatment for a specific condition. But due to the confidentiality of prices physicians are usually unaware of the relative costs of different treatment options and have no incentives to consider the price of pharmaceuticals in their prescribing decision(Danish Medicines Agency 2009). In most 
hospitals the wards are officially responsible for managing their own pharmaceutical budget; however there are no clear consequences if budgets are overspent.

There may be several reasons for the differential organisation of the market for hospital medicines and the pharmaceutical retail sector. Whereas over consumption of healthcare services due to moral hazard is believed to be a minor problem in the hospital sector, patient safety issues and high switching costs ,both pecuniary and organisational, play a bigger role in the hospital sector than in primary care. A successful procurement requires a lot of expertise and comprises much more than contracting for the lowest price only, but must secure timely availability of desired medicines in the required quantity at a recognised quality standard (Dawson 2008). Just as the design of regulation in the pharmaceutical retail sector, elements in the design of a tender contract, such as market exclusivity, contract length and publicity of prices may have important implications for competition in a tender market (Sammarco 2010). In contrast to the pharmaceutical retail sector, where prices are publicly available on the website of the Danish Medicines Agency and may be subject to change every 2 weeks, contract prices for hospital medicines are confidential and usually fixed for one year.

\subsection{The organisation of procurement of hospital medicines}

While the pharmaceutical retail market in Denmark is decentralised, the purchase of hospital medicines is highly centralized. $98 \%$ of all medicines used at public hospitals are bought through AMGROS, which was introduced in the 1990ies with the goal to limit pharmaceutical expenditures through the joint procurement of hospital medicines. Pharmaceutical products, patented as well as off-patent, containing substances with a total expected turnover of more than 0.5 million Danish kroner equivalent to about $67000 €$ per contract period are publicly tendered through AMGROS following the EU Directive for public procurement (Directive 2004/18/EC). The calls for tender are organized as firstprice sealed-bid procurement auctions, where the company with the lowest price or overall economically most advantageous offer wins the contract. All calls for tender are announced on AMGROS' homepage and the EU-ted database for public procurement (www.ted.europa.eu) specifying the type of framework contract and the demanded pharmaceuticals.

Before preparing the calls for tender the procurement agency consults hospital pharmacists and medical specialists to draft the tender award criteria for important products, in order to prevent pitfalls and achieve a satisfactory tender outcome. There are four kinds of framework contracts referring to the selection criteria of the winning bidder. Contracts may be either awarded to only one supplier exclusively or to several suppliers (parallel contracts). The latter option is primarily used in cases when special patient safety issues need to be considered and bidders only compete for the right to supply the treatment for new patients. Additionally to normal contracts, where price is the only decision criterion, AMGROS has the opportunity to include other product characteristics, such as packaging or easy handling in the tender. Then the bidder with the overall economically most advantageous offer wins the contract. The later requires evaluation of each offer by a tender committee that examines product samples to determine the winner of each contract based on predefined weighting criteria, which are specified in the calls for tender.

The calls for tender are very specific stating the exact pharmaceutical substance, anatomical therapeutic chemical (ATC) classification code (WHO Collaborating Centre for Drug Statistics Methodology 2008), strength, dispensing form, potentially package sizes and an estimate of the expected amount of units demanded of each pharmaceutical. Each tender number is a legally separated contract, bundling of products across tenders is 
not allowed and there is no reservation price. Opposed to pharmaceutical procurement practices in other countries as for example in Italy (Sammarco 2010), all calls for tender during our observation period were organised on the level of generic substitutability rather than therapeutic classes. Thus AMGROS can only fully exploit its purchasing power of competitive tenders in markets where a direct competitor is available. Typically the calls for tender are put up as national tenders covering all of Denmark and run over one to two years, but there have also been experiments with regional tenders and shorter contract periods in an attempt to increase competition and attract more bidders.

Suppliers are given ca. 45 days to prepare an offer and to submit a price per package in AMGROS' electronic tendering system at www.amgros.dk before the tender closing date. All pharmaceutical companies, wholesalers, parallel importers and manufacturers registered in the EU are potential participants in the tenders, however they must obtain marketing authorisation for their product prior to signing the contract. Products for which no offer was made have to be purchased at the official pharmacy purchasing price (PPP). To prevent supply shortages and speculative bidding, suppliers need to cover the extra costs for more expensive substitute medicines in case they do not comply with timely delivery. The following figure outlines the timeline for the procurement process.

Figure 1: The procurement process

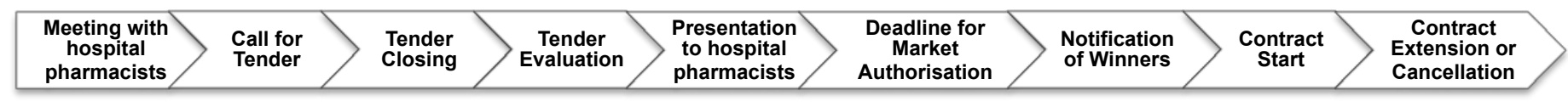

After the tenders have closed, the offers are evaluated and results presented to hospital pharmacists and specialists to implement the tenders. The winning firm is notified, however the winning price is not revealed. The pharmaceutical and therapeutic committees then update the formularies, listing the pharmaceuticals recommended for the use in public hospitals in their region, to direct pharmaceutical demand to products that have received especially favourable prices. This practice may induce considerable shifts in demand between products that are not generic substitutes after the tenders have closed, and may imply considerable uncertainty about the actual value for some contracts. Even if the volume could be predicted with absolute certainty there may still be uncertainty about the total value of the contract due to a preferred customer clause that enables AMGROS to buy the pharmaceutical for the official market price (PPP) if that price falls below the contract price. In addition to that AMGROS has the possibility to unilaterally cancel or extend the contract for an additional year without re-tendering the contract publicly. In contrast to the centralised pharmaceutical purchasing scheme for hospital medicine in New Zealand, hospitals in Denmark do not have to commit to purchasing targets for contracted medicines and no penalties apply if non-contracted medicines are purchased. AMGROS' purchasing strategy may therefore be characterised as a zero risk policy, as all financial risks involved in the procurement process are borne by the pharmaceutical companies.

AMGROS is financed through a $2 \%$ surcharge on the official pharmacy purchasing price (PPP) for products for which an offer was made. The final AMGROS sales price (ASP) paid by the regions is therefore equal to the PPP if no offer was made, or the contract price plus a $2 \%$ of the official PPP, whichever is lower. 


\section{Data \& Methods}

The dataset used for the empirical analysis is assembled from data provided by AMGROS. The dataset contains information on annual sales value and volume for each package purchased in Denmark between 2005 and 2009 in the pharmaceutical retail and hospital sector. ${ }^{1}$ Sales values are provided in pharmacy purchase price (PPP) and AMGROS sales price (ASP) and volumes are provided in number of packages and defined daily dosages (DDDs) as defined by the WHO (WHO Collaborating Centre for Drug Statistics Methodology 2008) or internal comparison unit if no official DDD was defined. Additionally the dataset contains detailed information on the supplier, the active substance, ATC code, dispensing form, concentration and package size of the medicines and information about the tender type used to procure the medicines for the hospital sector.

The following analysis presents volume weighted average prices. In the pharmaceutical retail sector prices refer to PPP and in the hospital sector to ASP, because policy makers are primarily interested in the real price paid for the medicines. The volume weighted average discount rate, defined as the difference between expenditures valued in the official PPP and ASP was about 19\% throughout the observation period although discounts for single products varied between 0 and $98 \%$. But for many hospital medicines the official PPP could be set at any arbitrarily high level since they do not have significant sales outside the hospital sector. Therefore a quantification of the savings from joint procurement as the difference between the official price and actual contract price is of little use.

To give a description of the nature of expenditures on hospital pharmaceuticals we first describe the distribution of pharmaceutical expenditures using key summary statistics, which are often used to compare pharmaceutical markets across OECD countries. Then we analyse how prices have developed over the last 5 years and which other factors contributed to the pharmaceutical expenditure increase. Pharmaceutical expenditure growth can be decomposed into three contributing factors: Changes in prices holding volume constant, changes in volume holding prices constant and changes in the product mix for example through the introduction of new substances.

There are several methods for calculating price indices, leading to different estimates of the impact of price changes on expenditures. The intention of this study is to provide a liberal estimate to avoid underestimation of the impact of price changes on pharmaceutical expenditures. Therefore a fixed Laspeyres price index is used, which reflects price changes for products already marketed in 2005 and is known to generally provide an upper bound for the average price increase (Rovira, Tremosa, Gilabert, \& Torralba 2001). This price index is calculated by weighing price changes over a given period with the consumption weights of the base period, which can be expressed by the following formula: $P I_{L}=\frac{\sum\left(p_{i t} * q_{i 05}\right)}{\sum\left(p_{i 05} * q_{i 05}\right)}$

Where $p_{i t}$ is the prevailing price per package or DDD of product $i$ in period $t$. And $q_{i 05}$ are the quantities consumed in the base period 2005. An important aspect in this analysis is the level of product aggregation, which should reflect what consumers regard as perfect substitutes for each other (Grilliches 1994). To assess how this choice affects the price index estimates we perform the analysis at two levels of product aggregation. At first we define a homogeneous product - as exact packages of the same producer. In the second analysis we define all products containing the same substances possibly from

\footnotetext{
${ }^{1}$ The data source for the pharmaceutical retail sector is DLI (www.dli.dk), which is also the source of the Danish IMS sales data.
} 
different producers as homogeneous. However the method for calculating the two price indices is the same.

The effect of changes in quantity for products already marketed in 2005 is measured using a Paasche volume index. This volume index is calculated using prices in the current period t to weigh volume changes for the products already marketed in the base period, which can be expressed through: $V I_{P}=\frac{\sum\left(p_{i t} * q_{i t}\right)_{\mid 05}}{\sum\left(p_{i t} * q_{i 05}\right)}$

Where $q_{i t}$ are the quantities consumed in the current period $t$, and $\sum\left(p_{i t} * q_{i t}\right)_{\mid 05}$ is the sum of expenditures in period $t$ for products that have already been marketed in 2005.The denominator is the sum of quantities of the base period valued at current prices, which is the same as the nominator of the Laspeyres price index. Multiplying the Laspeyres price index with the Paasche volume index yields the value index for products already marketed in $2005 \frac{\sum\left(p_{i t} * q_{i t}\right)_{05}}{\sum\left(p_{i 05} * q_{i 05}\right)}$.

Total expenditure growth $\frac{\sum\left(p_{i t} * q_{i t}\right)}{\sum\left(p_{i 05} * q_{i 05}\right)}$ can then be decomposed into a part that is due to the medicines that have already been marketed in $2005 \frac{\sum\left(p_{i t} * q_{i t}\right)_{05}}{\sum\left(p_{i 05} * q_{i 05}\right)}$ and those that have been introduced or taken from the market since $2005 \frac{\sum\left(p_{i t} * q_{i t}\right)-\sum\left(p_{i t} * q_{i t}\right)_{005}}{\sum\left(p_{i 05} * q_{i 05}\right)}$. Thus the difference between the expenditure growth index and the value index for products already marketed in 2005 can be interpreted as expenditure increase due to newly introduced substances, since no substances have been withdrawn from the market during our observation period. See Gerdtham \& Lundin 2004 for a similar decomposition analysis (Gerdtham and Lundin 2004).

\section{Results}

\subsection{Distribution of expenditures in 2009}

Since there are few private specialists in Denmark and most specialised treatment takes place in public hospitals the pharmaceutical market is not only separated with respect to its organisation, but also with respect to the medicines primarily sold in each sector. Many medicines that are primarily used in the hospital sector have no corresponding sales in the pharmaceutical retail sector and vice versa. 
Figure 2: Pharmaceutical sales in millions of DKK in the retail and hospital sector by main anatomic category in 2009 .

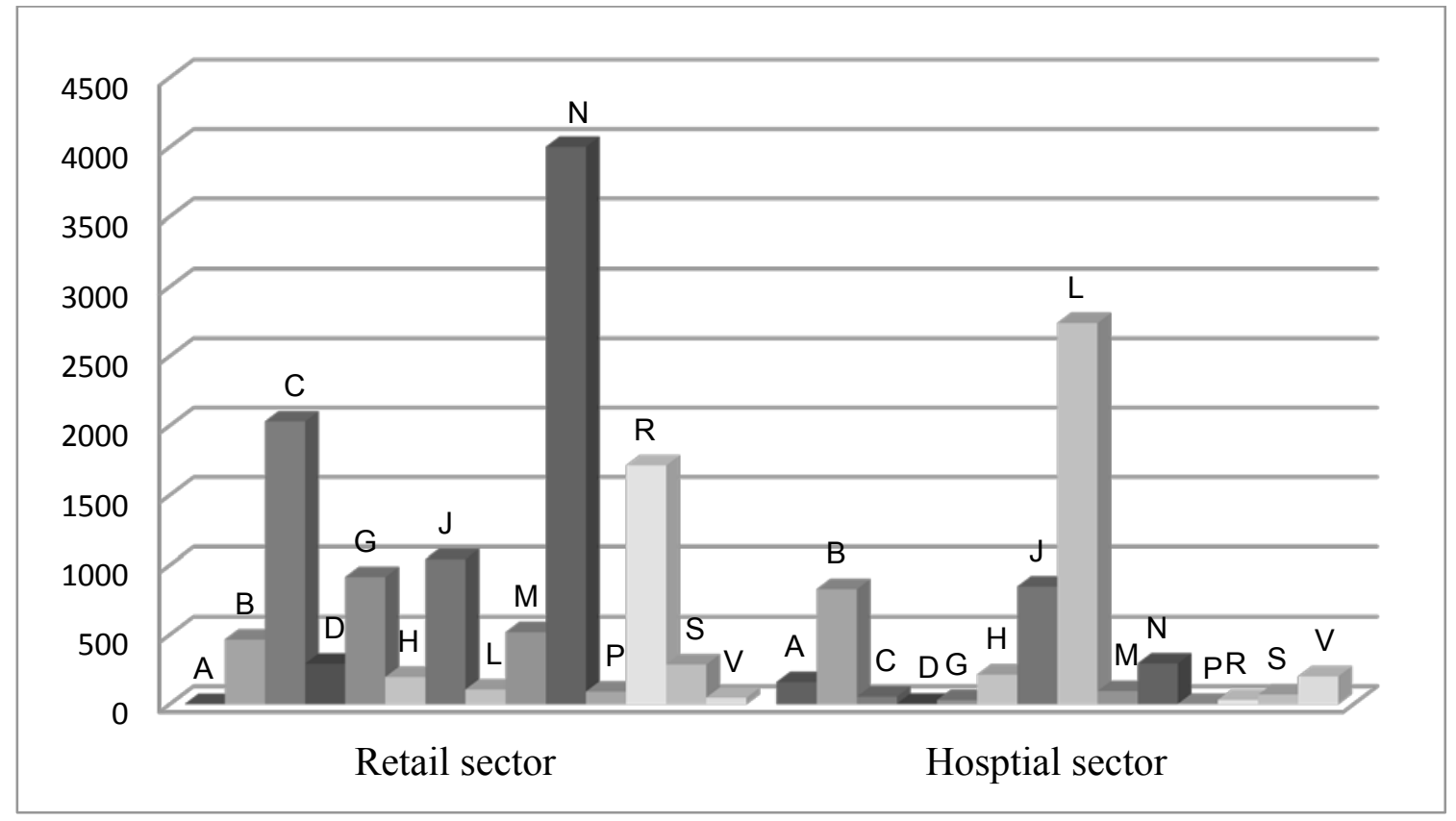

Pharmaceutical sales in the hospital sector are mostly concentrated on cancer treatment and other immune modulating agents, anti-infective and blood (forming) products (anatomic groups L, J and B), while expenditures in the pharmaceutical retail market are high for cardiovascular medicine, nervous system and respiratory system (anatomic group $\mathrm{C}, \mathrm{N}$ and $\mathrm{R}$ ). This implies that AMGROS could have considerable purchasing power in the market for hospital medicines to leverage prices.

The analysis of the distribution of pharmaceutical sales across pharmaceutical suppliers in 2009 shows, that the hospital sector is more concentrated than the retail sector. A measure that is often reported to describe the concentration in specific markets is the cumulative market share of the four biggest companies also known as C4. The proportions were calculated by dividing the pharmaceutical sales for each company by the total turnover generated in each sector. Table 1A shows that overall market concentration is higher in the hospital sector than the retail sector. However market concentration is lower than what competition authorities typically consider to be a dominant market position. But in the pharmaceutical sector this measure may be of little use because pharmaceutical companies often concentrate their activities on few therapeutic categories in which they have an advantage and generate a majority of their revenue from only a few products. $^{2}$

Table 1B shows the distribution of sales across the top selling substances. In 2009 there were more than 1000 pharmaceutical substances available, but the majority of sales are concentrated on very few products. The 100 top selling substances have a combined market share of $68 \%$ in the pharmaceutical retail sector and more than $84 \%$ in the hospital sector. This is primarily driven by the 25 most selling substances and suggests that the market for hospital medicine is more concentrated than the pharmaceutical retail market.

\footnotetext{
${ }^{2}$ In fact there are no generic producers nor parallel importers among the top 10 pharmaceutical companies in the hospital sector, whereas there are three in the pharmaceutical retail sector.
} 
Table 1A: Market concentration of the 4 largest pharmaceutical companies in 2009

\begin{tabular}{lllllll}
\hline \multicolumn{2}{c}{ Retail sector } & \multicolumn{5}{c}{ Hospital sector } \\
\cline { 4 - 6 } & Company & Market share & Cumulative & Company & Market share & Cumulative \\
\hline 1 & Nycomed & $6.8 \%$ & $6.8 \%$ & Roche & $12.0 \%$ & $12.0 \%$ \\
2 & Orifarm A/S* & $6.4 \%$ & $13.2 \%$ & Novartis & $8.2 \%$ & $20.2 \%$. \\
3 & Pfizer & $5.8 \%$ & $19.0 \%$ & Abbot & $6.7 \%$ & $26.9 \%$ \\
4 & Glaxo & $5.7 \%$ & $24.9 \%$ & Schering & $6.1 \%$ & $33.0 \%$ \\
\hline
\end{tabular}

* Defining Orifarm A/S and Orifarm Generics as separate companies

Table 1B: Distribution of sales by number of top selling substances in 2009

\begin{tabular}{lll}
\hline & Retail sector & Hospital sector \\
\hline 5 & $12.2 \%$ & $22.5 \%$ \\
10 & $20.6 \%$ & $35.6 \%$ \\
25 & $36.4 \%$ & $54.7 \%$ \\
50 & $51.6 \%$ & $70.7 \%$ \\
100 & $68.4 \%$ & $84.4 \%$ \\
\hline
\end{tabular}

In Table 2 pharmaceutical expenditures in each sector are grouped by pharmaceutical supplier and their membership in the Danish pharmaceutical industry associations. It can be seen that the share of the pharmaceutical industry association (Lif), representing most of the research based pharmaceutical companies, has a considerably larger share in the hospital sector than in the pharmaceutical retail sector. But the share of the parallel importers association (PFL) and the association of generic producers (IGL) are considerably lower in the hospital sector than in the retail sector. This may be due to the tendering process because it creates more pressure on medicines for which bioequivalent substitutes are available, but less pressure on new products for which no substitutes are available. In 2009 IGL members had a combined market share of about $18 \%$ of the total hospital market in terms of volume, but only $1.9 \%$ in terms of sales value.

Table 2: Distribution of annual turnover and volume shares across membership in Danish Pharmaceutical Industry Associations in 2009

\begin{tabular}{lcccccc}
\hline & \multicolumn{2}{c}{ LIF } & \multicolumn{2}{c}{ PFL } & \multicolumn{2}{c}{ IGL } \\
\hline & Turnover & DDDs & Turnover & DDDs & Turnover & DDDs \\
\hline $\begin{array}{l}\text { Retail } \\
\text { sector }\end{array}$ & $58.72 \%$ & $45.72 \%$ & $17.26 \%$ & $8.27 \%$ & $12.53 \%$ & $41.90 \%$ \\
$\begin{array}{l}\text { Hospital } \\
\text { sector }\end{array}$ & $76.36 \%$ & $64.93 \%$ & $4.99 \%$ & $3.29 \%$ & $1.94 \%$ & $18.35 \%$ \\
\hline
\end{tabular}

* Membership in an industry association is identified in the beginning of 2009. Suppliers are classified according to membership in LIF, PFL or IGL. Several pharmaceutical companies are not member in any industry association: about $11 \%$ of the sales in the pharmaceutical retail sector and $17 \%$ in the hospital sector correspond to the residual group that could not be allocated to any of these industry associations. The reported numbers relate to sales figures, hospital pharmacies' own production is not included. 


\subsection{Development of pharmaceutical expenditures and prices}

Table 3 shows the development of pharmaceutical expenditures in the pharmaceutical retail and hospital sector between 2005 and 2009. In this 5 years period pharmaceutical expenditures for hospital medicine have more than doubled, while the pharmaceutical retail sector has increased only moderately by about $15 \%$ during the entire period. In 2009 the market for hospital medicines made up more than $37 \%$ of the total Danish pharmaceutical market. However, the expenditure increase has slowed down slightly during the last 2 years.

\begin{tabular}{ll}
\hline Table 3: & $\begin{array}{l}\text { Annual expenditures and expenditure growth rates in the } \\
\text { pharmaceutical retail and hospital sector in billions of Danish kroner }\end{array}$ \\
& $(7.5 \mathrm{DKK}=1 €)$
\end{tabular}

\begin{tabular}{lccccc}
\hline & 2005 & 2006 & 2007 & 2008 & 2009 \\
& & & & & \\
Retail sector & 7.75 & 8.17 & 8.79 & 9.03 & 8.92 \\
$\begin{array}{l}\text { Total Expenditures } \\
\text { Annual growth rates }\end{array}$ & & 1.06 & 1.08 & 1.03 & 0.99 \\
$\begin{array}{l}\text { Hospital sector } \\
\text { Total Expenditures }\end{array}$ & 2.53 & 3.12 & 3.99 & 4.73 & 5.29 \\
Annual growth rates & & 1.23 & 1.28 & 1.19 & 1.12 \\
\hline * Expenditures in the pharmaceutical retail sector are valued in PPP and in ASP in the hospital sector.
\end{tabular}

In order to analyse which factors contributed to the sharp increase in pharmaceutical expenditures in the market for hospital medicines we perform a decomposition analysis using price and volume indices. First we determine the price increase for exact packages identified by their unique product identification number. We find that prices for pharmaceutical packages that have been marketed since 2005 have decreased by $4 \%$ in the pharmaceutical retail sector and increased by $5.6 \%$ in the hospital sector between 2005 and $2009^{3}$. However this is neglecting the price effect of generics medicines that were introduced in the meantime. A more informative price index may therefore be one that uses average prices at the substance level, which enables us to identify what part of the expenditure increase was due to the introduction of new substances. Table 4 shows the decomposition of the expenditure growth into the contributions from price and volume changes for substances marketed since 2005, and the introduction of new substances. The price index for substances has increased by only $4.8 \%$ in the market for hospital medicines, and has even decreased by about $7 \%$ in the pharmaceutical retail sector. A larger part of the expenditure growth can now be explained by expansions in volume, which reflect increased treatment activity and contributed around 16\% to expenditure growth in the retail sector and about $77 \%$ in the market for hospital medicines. The introduction of new substances, which may be interpreted as an increase in treatment efficiency accounts for about $24 \%$ of expenditure growth in the hospital sector and $6 \%$ in the pharmaceutical retail sector.

Table 4: Decomposition of the expenditure growth due to price and volume increases and the introduction to new substances

\footnotetext{
${ }^{3}$ Results not shown, but available from the author upon request.
} 


\begin{tabular}{lccccc}
\hline & 2005 & 2006 & 2007 & 2008 & 2009 \\
\hline Retail sector & 1 & 1.055 & 1.122 & 1.148 & 1.139 \\
Expenditure Index & 1 & 0.981 & 0.990 & 0.969 & 0.925 \\
Price Index & 1 & 1.074 & 1.121 & 1,141 & 1.162 \\
Volume Index & 0 & 0.001 & 0.012 & 0.042 & 0.063 \\
New substances & 1 & 1.235 & 1.579 & 1.870 & 2.090 \\
Hospital sector & 1 & 1.012 & 1.101 & 1.077 & 1.048 \\
Expenditure Index & 1 & 1.204 & 1.370 & 1,609 & 1.777 \\
Price Index & 0 & 0.026 & 0.165 & 0.335 & 0.242 \\
Volume Index & & & & & \\
New substances & & & & & \\
\hline$* *$ Decomposition analysis covers only products for which defined daily dosages were available & \\
\hline
\end{tabular}

Splitting the market for hospital medicines into medicines that are purely hospital products and those that are active in both sectors reveals that the price increase in the hospital sector is mainly driven by hospital-only medicines, as the price index for substances that are common in both sectors decreased by $3.4 \%$ between 2005 and $2009^{4}$.

\section{Discussion}

The article presents the market environment for hospital medicines in Denmark between 2005 and 2009. It provides a description of the tendering and procurement process in order to advance the understanding of how tendering is used in practice in Denmark. Tendering was introduced in Denmark long before our observation period began. To assess the performance of the present institutional set-up the study decomposes pharmaceutical expenditure growth in both sectors and describes the concentration of pharmaceutical expenditures using key summary statistics, which are often used to compare pharmaceutical markets across OECD countries.

Pharmaceutical tenders are made at bioequivalence level, to interfere as little as possible in the treatment decision, while seeking low pharmaceutical prices. In contrast to group purchasing schemes in other countries, for example as used in New Zealand, hospitals are not penalised for purchasing non-contracted medicines in excess of agreed limits, but have an outside option to purchase pharmaceuticals through retail pharmacies. However this may limit the possibilities to leverage the procurement agency's purchasing power to obtain discounts for products for which no exact bioequivalent substitutes are available. Thus more commitment on the side of the hospitals may be needed to implement tenders for analogue substitutes in order to increase competition among therapeutic alternatives that have so far been largely unaffected by tendering. In January 2010 RADS, a new committee was created to align pharmaceutical use for expensive medical treatments across the Danish hospitals, and to work towards a consensus and binding clinical guidelines so that tenders for analogue substitutes may be implementable in the future (Danske Regioner 2010).

\footnotetext{
${ }^{4}$ Substances that are common in both sectors are here defined as having at least $30 \%$ of sales in the primary sector. Results not shown, but available from the author upon request.
} 
While there are several institutions that attempt to affect prices in the pharmaceutical retail sector, AMGROS was the only institution aimed at containing pharmaceutical prices in the hospital sector during our observation period. Unlike in the primary sector pharmaceutical companies are not required to provide cost-effectiveness assessments before getting access to the market. Indeed our analysis showed that a major part of pharmaceutical expenditures was spent on new pharmaceuticals and the expenditure share on products that have a direct competitor from parallel imports or generic alternatives is considerably lower than in the retail sector.

The low share of parallel imports in the market for hospital medicine may be a result of insufficient incentives for parallel importers to participate in the tenders or difficulties to source enough medicines in other countries. Distribution channels for hospital medicines are limited and therefore easier to monitor for originator manufacturers. Confidential rebating in other European countries may exacerbate this effect, since it enables originator manufacturers to circumvent EU reference price systems and maintain price differentials between EU countries. A recent report from an EU-project on pharmaceutical tendering in Europe showed that 17 out of 20 European countries use tendering procedures to varying extends for the procurement of hospital medicines (Leopold, Habl, \& Vogler 2008). Empirical research is needed to elicit the extent of potential spill-over effects of pharmaceutical tendering to other countries.

Another remarkable finding is that the share of the generics association is much lower in the hospital sector than in the pharmaceutical retail sector. The lower price per DDD for medicines of IGL members in the hospital sector may suggest that AMGROS has considerable market power and the tendering process creates fierce price competition in markets where generic substitutes are available. However considering that most hospital medicines do not have corresponding sales in the pharmaceutical retail sector, suppliers may drop out of the market in the long run or not enter in the first place, thus tenders may create a potential barrier for entry. The organisation of procurement may therefore impact industry structure in the long run. The generics associations across Europe are lobbying heavily against the use of tendering procedures in the retail sector. They argue it creates substantial pressure on prices for off-patent medicines and increases the risk to be excluded from the market (Carradinha 2009). Making contract prices publicly available after the tenders have closed could increase transparency and attract more competitors, but could also increase the potential for collusion amongst suppliers.

Since 2005, expenditures for hospital medicines have more than doubled, while increasing only slightly in the pharmaceutical retail sector. This raised the attention of policy makers in 2009, who introduced policy initiatives to limit spending on hospital medicines. But since the expenditure decrease in 2009 was even higher in the pharmaceutical retail sector, it is questionable whether the slower expenditure growth in the hospital sector in 2009 was due to the introduction of a price limit ratified in June 2009, or an effect of other market forces (Ministry of Health and Prevention 2010).

The decomposition analysis showed that the higher expenditure growth for hospital medicine was mainly due to a higher introduction rate of new substances and increased utilization, while price increases were only moderate. The expansion in utilisation of substances that were already marketed in 2005 has contributed the lions share to pharmaceutical expenditure increase. This may be the result from introducing case based financing for hospital services in Denmark in 2004 to increase hospital activity, leading to more intensive pharmaceutical treatment. The pharmaceutical expenditure growth from an expansion in volumes therefore reflects to a large extend an intended expansion in treatment activity. 
The second biggest factor contributing to the sharp increase in expenditures for hospital medicines was the introduction of new substances. New medicines are often more effective than older medicines and may therefore reflect increased treatment efficiency. If medicines are more efficient substitutes for other healthcare inputs they may contribute to an overall cost containment strategy. But if new medicines treat previously untreatable diseases even the introduction of very effective medicines result in an efficient increase in healthcare expenditures that needs to be covered from external sources. It cannot be assessed from this analysis whether the increase in expenditures has been efficient, but the fact that excess pharmaceutical expenditures could not be covered by hospitals internally suggests that it had at least not led to savings in other hospital services of the same magnitude.

Only a small part of the expenditure growth was actually caused by price increases for drugs that were already marketed in 2005. The average price increase for hospital medicine was lower than the increase of the Danish Consumer Price Index for the same period, but higher than in the pharmaceutical retail sector. This suggests that the scope for limiting pharmaceutical expenditure growth through a price ceiling regulation, which requires that pharmaceutical firms cannot increase package prices again if they are once lowered, would be limited. The level of product aggregation for calculating the price indices did not greatly affect our results and therefore it may be concluded that price increases were not the major driving force behind the expenditure increases in the market for hospital medicines.

\section{Acknowledgement}

This study was financially supported by AMGROS, the Danish public procurement agency for hospital medicines. AMGROS staff Trine Kart Sørensen, Flemming Sonne, Ulla Ege Johansen and Peter Helmbæk contributed with valuable interpretation of the data. Additionally, Christian Kronborg and Jacob Arendt Nielsen and participants of the 2010 Danish Forum for Health Economics have commented on an earlier draft of the article and are hereby gratefully acknowledged. Publishing the content of this article does not provide any financial benefits to the author.

* Correspondence to: Gisela Hostenkamp, PhD-student, Research Unit for Health Economics, Institute of Public Health, University of Southern Denmark, J.B. Winsløws Vej 9B, DK-5000 Odense C, Denmark. E-mail: gih@sam.sdu.dk 


\section{References}

Brereton, S. 1999, Pharmaceutical Procurement and Pricing in European hospitals.

Carradinha, H. 2009. Tendering short-term pricing policies and the impact on patients, governments and the sustainability of the generic medicines industry. Journal of Generic Medicines, 6, 351-361 available from:

http://www.ingentaconnect.com/content/pal/jgm/2009/00000006/00000004/art00008; http://dx. doi.org/10.1057/jgm.2009.29

Danish Medicines Agency 2010, Prices and Reimbursement, accessible online at http://www.dkma.dk/1024/visUKLSArtikel.asp?artikelID=1469 (accessed dec 2009).

Danske Regioner. RADS Commission for the Use of Expensive Hospital Medicin (Rådet for Anvendelse af Dyr Sygehusmedicin (RADS) ). 2010. 20-1-2010.

Ref Type: Online Source

Dawson, C. 2008, Cost containment in the pharmaceutical sector, European Social Insurance Platform http://www.peer-review-social-inclusion.eu/peer-reviews/2008/costcontainment-in-the-pharmaceutical-sector-innovative-approaches-to-contracting-whileensuring-fair-access-to-drugs/stakeholder-esip/download ( accessed March 2010).

Faunce, T.A., Lofgren, H., Harvey, K., \& Johnson, K. 2006. Tendering for low cost generics in Australia. Health Issues, 87, 26-29

Gerdtham, U.G. \& Lundin, D. 2004. Why did drug spending increase during the 1990s?: A decomposition based on Swedish data. Pharmacoeconomics, 22, (1) 29-42

Hudson, J. 2000. Generic take-up in the pharmaceutical market following patent expiry: A multi-country study. International Review of Law and Economics, 20, (2) 205-221 available from: http://www.sciencedirect.com/science/article/B6V7M-4118FKP3/2/daa3df8d8b9c1ea00055979308a7cedc

Kanavos, P., Seeley, L., \& Vandoros, S. 2009, Tender systems for outpatient pharmaceuticals in the European Union: Evidence from the Netherlands, Germany and Belgium.

Leopold, C., Habl, C., \& Vogler, S. 2008, Tendering of Pharmaceuticals in EU Member States and EEA countries: Results from the country survey. Final Version, available online at http://ppri.oebig.at/Downloads/Publications/Final_Report Tendering June 08.pdf (accessed January 20th 2010).

Lif 2007, Pricing and Reimbursement in Denmark by Lif The Association of the pharmaceutical industry, available online at:

http://parno1.ipapercms.dk/LIF/Notater/PricingandreimbursementinDenmark/ (accessed June 2009).

Milovanovic, D.R., Pavlovic, R., Folic, M., \& Jankovic, S.M. 2004. Public drug procurement: the lessons from a drug tender in a teaching hospital of a transition country. European journal of clinical pharmacology, 60, (3) 149-153 
Ministry of Health and Prevention 2009, Analysis of hospital medicine (Ministeriet for Sundhed og Forebyggelse Analyse af sygehusmedicin: Rapport fra arbejdsgruppen om sygehusmedicin), available online at:

http://www.sum.dk/Aktuelt/Publikationer/ /media/Filer\%20-

\%20Publikationer_i_pdf/2009/Analyse\%20af\%20sygehusmedicin.ashx (accessed June 15th 2009).

Ministry of Health and Prevention 2010, Agreement on Price ceiling and price reductions for hospital medicine between Lif and Ministry of Health and Prevention (Aftale om prisloft og prisreductioner for loegemidler til sygehuse) (June 2009), available online: http://www.lifdk.dk/graphics/Lif/dokumenter/PDF/Aftale\%20om\%20prisloft\%20og\%20prisre duktioner\%20for\%201\%E6gemidler\%20ti1\%20sygehuse.pdf (accessed June 2009).

Møller Pedersen, K. 2003. Pricing and reimbursement of drugs in Denmark. The European Journal of Health Economics, 4, (1) 60-65 available from: http://dx.doi.org/10.1007/s10198-003-0165-6

Mooney, G.H. 2003. Economics, medicine and health care Pearson Education.

OECD 2008, Pharmaceutical Pricing Policies in a Global Market, available online http://www.oecd.org/document/36/0,3343,en $26493392941000996 \quad 1 \quad 1 \quad 1 \quad 37407,00 . h t m l \#$ How to obtain this publication (accessed June 2008).

OECD 2009, OECD Health Data 2009: Statistics and Indicators for 30 countries.

Rovira, J., Tremosa, R., Gilabert, A., \& Torralba, M. 2001. The role of prices in drug expenditure analysis. The European Journal of Health Economics, 2, (4) 142-149

Safiye Er Danish Medicines Agency 2009, PHIS Pharmaceutical Health Information System Denmark PHIS Hospital Pharma Report Final Version, Commissioned by the European Commission, Executive Agency for Health and Consumers (EAHC) and the Austrian Federal Ministry of Health (BMG)

http://phis.goeg.at/downloads/hospitalPharma/PHIS\%20Denmark\%20Hospital\%20Pharma\%2 0Report\%202009.pdf (accessed Jannuary 20th 2010).

Sammarco, C. 2010. Competition in Public Bidding Exercises for Pharmaceutical Products. Opinio Juris in Comparatione, 2, (4) available from: http://ssrn.com/abstract $=1647613$

Scott Morton, F.M. 1999. Entry Decisions in the Generic Pharmaceutical Industry. The RAND Journal of Economics, 30, (3) 421-440 available from: http://www.jstor.org/stable/2556056

Tordoff, J.M., Norris, P.T., \& Reith, D.M. 2005. Managing prices for hospital pharmaceuticals: a successful strategy for New Zealand? Value in Health, 8, (3) 201208

Tordoff, J.M., Norris, P.T., \& Reith, D.M. 2008. " Price Management" and Its Impact on Hospital Pharmaceutical Expenditure and the Availability of Medicines in New Zealand Hospitals. Value in Health, 11, (7) 1214-1226

WHO Collaborating Centre for Drug Statistics Methodology 2008, Guidelines for ATC classification and DDD assignment 2009., http://www.whocc.no/atc_ddd_publications/guidelines/(accessed February 1st 2009). 